\title{
Level of moral development of adolescents susceptible to antisocial behavior
}

\begin{abstract}
Summary
This study sought to recognize the level of moral development of adolescents who have committed an antisocial behavior and those who are prompt to it. For this purpose, research was carried out following the constructivist paradigm with a descriptive qualitative design. Participants were adolescents who have incurred the commission of any antisocial behavior and those who are likely to commit it, who attended a course of Culture of Legality along eight sessions. This course has been implemented in both school and nonschool environments, to discuss moral dilemmas, and moral reasoning to investigate the moral development. According to the theory of Kohlberg, the level of moral development of adolescents before and after the course was a constant variation between the preconventional and conventional level.
\end{abstract}

Keywords: moral development, antisocial conduct, adolescence, culture of legality family, school, neighborhood, environments, friends, psychosexual, social levels, physiological changes, antisocial behavior, temperament, impulsivity, community

\author{
Volume 2 Issue 5 - 2018
}

\author{
Yolanda Heredia Escorza, Denisse Carolina \\ Cruz Ornelas \\ Tecnológico de Monterrey (ITESM), Col.Tecnológico, Mexico
}

Correspondence: Yolanda Heredia Escorza, Tecnológico de Monterrey (ITESM),Av. Eugenio Garza Sada 250I Sur, Col. Tecnológico C.P. 64849, Monterrey, NL, México, Email yheredia@itesm.mx

Received: September II, 2018 | Published: September 20, 2018

\section{Introduction}

Adolescence is the transition between childhood and adulthood, this stage characterizes by biological, morphological and physiological changes, and within these three changes the sexual, psychosexual and social levels develop. All these changes place the teenager in a time of uncertainty and confusion, which can be seen reflected in absentia and making bad decisions. At the stage of identity development, becomes important to find out who they are and where to go; this is why, the environments in which the adolescent develop (family, school, and neighborhood) are important. ${ }^{1}$ Among the physical and psychological changes in the adolescent are: increased or decreased self-esteem, greater emotional understanding, the perception of capabilities, characteristics, and the relationship they have with the opportunities. Identity builds from an early age; also, the image and likeness of parental figures and cultural environment of the person. But; in adolescence, a critical review of the personal identity fundamentals is made with other patterns of behavior and personal conscience is sought, often accompanied by a separation tendency of adult models and identification with the culture of teenagers or even themselves. As a result, this can put young people at risk and to make bad decisions, for this urgent they need to consolidate a distinct personal identity of the adult and the need to be accepted by peers. Making bad decisions can result in anti-social behavior where the young teenager is prone to the commission of anti-juridical actions or criminal behaviors. Another way of putting it is that the young person is at risk of assuming a negative identity (Erikson, 1968 cited by Arnett, 1998).

The teenager is isolated from its first socialization environment; that is to say to their family, then goes to find company among his peers or friends (Sierra, Reyes, and Cordoba, 2010 cited by Tesouro et al., ${ }^{1}$ Given the need for reassurance, friends are an important influence on the adolescent, while the standards imposed are accepted within the group and identify the values and rules of friends, as a way to separate from the family. In this frame of building identity, one of the important aspects is the moral development. Moral development is part of the psychological aspects and other spheres of the individual; it develops gradually, and the individual's environment influences it. Among theories explaining moral development, Lawrence Kohlberg, based on the theory of Jean Piaget who was his professor, refines the moral development theory. Moral development is the result of the interaction between the characteristics of the individual about the conditions of the environment it fosters. Kohlberg's ${ }^{2}$ studies (1992) show that mature or full moral development not only is reached by age, but it is necessary also the maturity of the moral judgment; like Piaget noticed in his studies. Therefore, it creates the scheme of moral development taking into count six progressive phases in which the child, the teenager, and the adult are included. ${ }^{3}$ On the transition to maturity, it is necessary to pass through the cognitive conflict where the individual confronts a problematic situation (dilemma). The individual realizes that his mental structure is not enough to solve it, this creates a new structure. The determinant factor that influence in moral development are cognitive development and the social experience. $^{4-6}$

The development scheme bases on three levels: pre-conventional, conventional, and post-conventional. Each level subdivides into two states which are similarly measurable through chronological age and cognitive level. Thereby, the pre-conventional level has two states: State 1 - punishment and obedience, State 2 - purpose and exchange. In the conventional level, the states are State 3 - expectation and interpersonal accordance, and State 4 - social system and awareness. These states characterize by being appropriate to fulfill acquired duties, and to follow the law unless it gets between some personal custom and the contribution to society. In the post-conventional level, the states are State 5 - previous rights and social contract, and State 6 - universal ethical principles. This level indicates that the individual has developed consciously by the diversity of the opinions and values; most of them relate to a social level. Family values should not be kept as part of the social contract because it acts according to the universal values of justice, equality, respect, and dignity. ${ }^{4}$ Antisocial behavior defines as the commission of typical and unlawful conduct as an offense in the Mexico state Penal Code. In other words, these are acts that force the law. There are different risk factors that cause the commission of criminal acts by a teenager which, have been analyzed with the purpose to create integral prevention programs. Risk factors are: familiar, social (school, neighborhood, etc.) and individual (temperament, impulsivity, and attention problems). ${ }^{?}$

Familiar factors measure the family dissemble, conflicts, 
violence, abuse and parenting style. Negative parenting styles have a strong impact on the child behavior. ${ }^{7}$ Social factors comprehend communication media and violence in which the child is exposed; this provokes to become something daily and regular. When the school is in a crisis of values, it offers an unbalanced environment for children. Among individual factors is the temperament. The character of the child is the cornerstone of the social and personal development. ${ }^{7}$ Garaigordobil ${ }^{8}$ analyzed the relation between antisocial conduct and diverse socio-emotional factors on adolescents, to identify the antisocial conduct predictors and see if there is any difference between genders. The sample was formed by 174 teenagers between 12 and 14 years old, of the first and second year of secondary school, within socio-economic and cultural medium levels, with 84 males and 80 females. The used instrument was: The Scale of Antisocial Behavior (ASB), the Self-Concept Scale, and the Assessment Questionnaire of Empathy (QE). Results indicated a relation between antisocial behavior and negative social behaviors, as prejudiced and impulsive attitudes of low academic performance, under the auto concept, aggressiveness, retreatment, etc. The aggressive behaviors include: Lack of prosocial behaviors, impulsivity, little consideration for others, self-concept, etc. About differences between genders, males are the majority in the commission of antisocial behaviors, but the difference is not significant. It established the need for intervention of socio-emotional programs during childhood to prevent the antisocial behavior of adolescence.

In their study, Espinoza, Clemente \& Vidal (2002), ${ }^{9}$ examined the bond between antisocial behavior and moral development in children; the hypothesis established that the antisocial behavior does not have a relationship with the moral development, and that there are factors which explain the moral thinking of the teenager that commits antisocial behaviors. The sample for this study was of 523 males and females between 9 and 18 years old, which were applied to Questionary A-D of antisocial behaviors of six fingers measured with the Objective Moral Partner Development (SROM). Results established that only some aspects of the antisocial behavior have relationship with moral development, creating a need to determine which factors are linked with moral development. ${ }^{9}$ Bandura (cited by: ${ }^{10,11}$ Professor of Stanford and expert speaker of explicative theories of criminal behavior, shows that children who display aggressive behavior and is reinforced, more frequently repeat the same behavior in comparison with children that are not punished for aggressive behavior. Bandura was firmly convinced that behavior is learned, no matter if it's aggressive or appropriate..$^{10,11}$ Antisocial behavior is the commission of a typical unlawful behavior classified as an offense under the Penal Code of Mexico state and commit by a teenager between 12 and 18 years old. On 1995 David Lykken developed a model to explain the origin of this behavior. This model shows how some temperament characteristics create problems to socialize in high manners, and results on problems to develop consciousness. The temperament characteristics that Lykken considers are impulsivity, fearlessness and sensation seeking. His study was made by comparing a simple of inmates and free individuals. The hypothesis establishes that these characteristics are more present on criminals. The applied instruments were the Difficulties Scale Temperament Canto Blanco Reduced (TCD -R) and the scale of Zuckerman sensation seeking. The study results show that the sensation seeking and fearlessness are higher on criminals, but impulsivity is minor. The reason may be that what is considered delinquent impulsivity is due to the consumption of some unnerving, or they were sensitized for being in prison. ${ }^{11}$
In addition to the relationship between the temperament characteristics as the source of antisocial behavior, the family interaction may be taken into account. The family is the principal socializing agent, in an environment where there are no bonds between the family members, there is no respect for the rules, Social conscience is not developed. Therefore there won't be bonds with society. ${ }^{12}$ Rodriguez and Torrente established how the factors maladaptive behaviors, incorporation of women to the working market, the rise of divorces, separations, and single-parent families (all factors are relative, exclusive with change of relatives.) Their research hypothesis was to meet the variables related to the family environment, the education and the influence on teenagers declaring to commit any antisocial behavior and those who declare the opposite. The study was made with 374 students between 11 and 17 years old. The instrument was The Family Social Climate Scale. The results show that strong emotional bonds between the members of the family allow the socialization. Also, the transmission of rules These family dynamics with the promotion of social, recreational, moral, and religious activities, isolates the children from antisocial behaviors. ${ }^{12}$ Teenagers commit antisocial behaviors, not crimes; they are not subject to criminal law. The terms sanctions and procedure change in comparison with the criminal adults. As a result of the Convention on the Rights of the Child adopted by the United Nations (UN) in 1989, the individual and social rights of children; including guarantees, were listed during the process, defined by the commission of antisocial behavior. Mexico accepts and endorses the convention in 1990 by acquiring the commitment to update and adapt its legislation. The dogmatic part of the Constitution of the United Mexican States covers all Mexicans regardless of age; although, criminal procedural guarantees are recognized only for those over 18 years of age. ${ }^{13}$

The protection system of juvenile offenders was reformed according to guarantees of legal certainty guaranteed to minors. Currently, there is a law responsible for the prevention of antisocial behavior, resolution of the technical and legal status of children and their rehabilitation; this is the Law of Social Prevention and Treatment of Minors of the State of Mexico, which guarantees the rights of minors. Specialized bodies apply this law; it regulates the actions of the State to create conditions for welfare and prevent antisocial behavior. Juvenile offenders are no longer subjects to the Guardian Council. This system provides authority to the General Directorate of Prevention and Social Rehabilitation, the Decider College, juvenile councils and juvenile preceptories (Act Social Prevention and Treatment of Minors in the State of Mexico, 1995). For this research, the authority of interest will be the juvenile preceptories. The juvenile preceptories of social integration are externalization areas where the teenager receive guidance, protection, and treatment. They are part of a program of educative, formative, and therapeutic activities which conceal children and their families (Regulation of the Regional Juvenile Social Reintegration Preceptories of the State of Mexico, 2013.) Orientation, protection, and treatment measures have a cornerstone on education, discipline, and work to integrate the teenager to society and their family. Within the educational regime, it integrates the academic, civic and ethical ambits, among others. This is where the teaching course Culture of Legality takes part. (Law of Justice for Adolescents of the State of Mexico, 2006.). Juvenile preceptories create and perform the Prevention of the anti-socialization program through action to detect and resolve the related factors with the origin of antisocial conducts, by applying the reintegration program (Regulation of the Regional Juvenile Social 
Reintegration preceptories of the State of Mexico, 2013). Without a doubt of the great importance that teenagers have at fulfilling their and moral development goals. Moral development refers to the ability to distinguish between what is appropriate and inappropriate under moral norms which integrate it. Development of this ability is the distinction which corresponds to parents and professors, with the objective to join as socially responsible citizens. ${ }^{14,15}$

The culture of legality is to meet, respect, follow and promote the law that integrates, and make people socialize peacefully according to the law. To reach the moral development goals, it is necessary that people receive instruction about culture of legality, moral thinking and decision making based on the law, from a very young age. ${ }^{14}$ As established before, antisocial behavior is standardized by the penal code as a crime made by a teenager between 12 and 18 years old. It is such behavior that attacks social order, and it is necessary to detect risk factors to prevent it or to give treatment to reintegrate the teenager to society as established by the Juvenile preceptory regulations. On the Culture of legality on the Regiomontana Family research made by Manuel Yarto Wong (n.d.) ${ }^{16}$ mentions the necessity to analyze the reasons that are motive to criminal violence, this raised two affirmations: the rule of law does not impose the lack of respect to law and the deception to authorities. This raises the objective to explore the culture of legality within families. A discussion group was formed by four couple of parents with four female and male teenagers between 12 and 17 years old; the academic level made the difference in the discussion group. Results showed that law is promoted through school. Teenagers don't live in a culture of legality; people respect more foreign law than their own and distrust authorities. It is noted that criminals are disguised among society and authority (Yarto, $\mathrm{n} / \mathrm{d}$.) In 1994, ${ }^{16}$ George Lind made a research named Why young offenders earn a little on moral discussion programs? He established that moral discussion programs of Kohlberg's type had little or short period effects on juvenile criminals or any who had positive results was for an extensive educative effort than those who are hypothetical. The second idea was that criminals could present more resistance to moral discussion programs, because of their antisocial posture which they have to overcome first. The study was made with 48 juvenile inmates between 15 and 23 years old, using the Moral Judgment Test (MJT) The results affirmed that criminals have a better ability to apply their moral principles to the discussion and the moral dilemma solutions. By comparing moral judgment with those who are not criminals and the inmates, moral judgment of inmates did not get better during the intervention where real moral dilemma about their life in prison were used. Concluding that, hypothetical moral dilemma creates a learning situation compared with a real dilemma which generate anxiety and that people refuse to participate in the discussion. Also, that extensive duration programs are necessary to meet the effects on criminals. ${ }^{17,18}$

Zerpa, Henriquez, and Ramirez (2006) made a study of the Measurement of the moral development, by applying the Definition of Criteria Test (DIT) to 39 men and 11 women between 19 to 55 years old, whose penalty was being fulfilled out of the prison. The results showed that most of them punctuate in a conventional level of moral development. ${ }^{19}$ Compliance with the rule of law has become an elusive goal. Dishonesty and honesty are rooted, even in cultural practices; this leads to distrust and therefore to no cooperation. The real problem is the fulfillment of the law and not if the law is good or bad. ${ }^{20}$ The focus of this research were teenagers that committed antisocial behavior, those who are considered in a state of risk, and those who are prompt to the commission of antisocial behavior. This research was only made in the region of Texcoco in the state of Mexico. Statistics for juvenile delinquency at national level shows that three of each ten criminals are teenagers. The main crimes are burglary, injury and narcotics related. $23 \%$ of the criminals are between 16 and 17 years old, and $7.38 \%$ are between 18 and 19 years old ${ }^{3}$ According to a comparative study of the juvenile delinquency index in the country made by the Superior Court of the Federal District in 2011, the state of Mexico was placed as an entity with high criminal levels with 3,106 cases against teenagers. ${ }^{21}$ The characteristics of teenagers prompt to the antisocial behavior are aggression, disobedience, addictions, domestic violence, school dropout, low self-esteem, etc. According to Mexico state newspaper, My Safe School program, 1,580 teenagers at risk were detected, but this is not official information. According to the reasons to start the Juvenile Justice Law in the state of Mexico, the commission of antisocial behaviors are increasing because of the changes in behavior, lifestyle, and situations that promote social exclusion and inappropriate behavior. This research established the next questions: Which is the level of moral development on teenagers between 12 and 18 years old with antisocial behavior or prompt to commit it? Which are the characteristics on teenagers that attend to the Preceptor of Juvenile Reintegration of Texcoco in Mexico state? Which is the moral development level of the parents of the teenagers?

\section{Methods}

Research methodology followed the constructivist paradigm with a qualitative-descriptive type; this kind of research produces descriptive data. ${ }^{22}$ It was fundamental to understand how participants construct and give meaning to their world. Through this approach describes how the participant understands their reality in their natural environment and context. ${ }^{6}$ The sample for this research was mixed; it was considered a convenience sample because participants were part of a treatment program for their antisocial and criminal behavior. Participants gather in a single place to fulfill their penalty. It is also an extreme case sample as it expected to analyze the level of moral development of teenagers that had presented antisocial behavior are considered prone to a state of risk by the commission of antisocial behavior. Therefore, it is considered the sample was formed by teenagers out of a regular situation (Creswell, 2005, cited by Hernandez et al., 2010.). The context, in which this research was made, was by the Regional Juvenile Social Reintegration Preceptory. This is a space where teenagers between 12 and 18 years old and young adults between 18 and 23 years old are part of treatment, and their parents receive information, orientation, prevention, protection, and treatment measures about topics as addictions, violence, family disintegration, norms, and values, etc. Also, they have sports, culture, community service, and labor training as extra activities; plus they receive personal attention from medics, psychologists, educationist, and social workers. To respect the underage participants' privacy, individual research for each person was not made.

According to INEGI $(2010)^{23}$ annual report, antisocial behaviors are identified as offenses in the criminal law. The crimes committed by the processed minors around 18 years old during 2009 were burglary, beatings, injuries, homicide, rape, sexual abuse, dispossession, vehicle theft, housebreaking, kidnapping; it can be inferred that these are the behaviors which by teenagers are fulfilling with an outsourcing treatment. This research included 15 teenagers between 13 and 18 years old with 13 males and two female participants. The period of the treatment for each participant is determined by the prevention workers, resulting in the changing of participants during the making of 
this research. The Preceptory of Juvenile Reintegration, in which this research took place, requires the presence of a parental supervisor or tutor during their treatment, the research also features the participation of 9 parents, which 2 were males and 7 were female between 33 and 52 years old. The instruments were used to gather information about moral development level, antisocial behavior, adolescent stage, and sociodemographic data. Tab view (register of thinking format.) The participant teenagers were part of the Culture of legality course; this course had 8 lessons and based on the moral statement of Alfonso Reyes. Each lesson shows the content and a moral dilemma. Moral dilemmas are a didactic strategy to promote the moral thinking created by Kohlberg. The course has workbooks for the participants and is a way for the teenagers to express their moral thinking. The observation guide was filled in by the course students before reviewing the content for the lesson and after checking the material. The objective of the register was to compare the discussion of the dilemma to detect any change in their thinking, and it was designed by the researchers.

A journal for each session was also used. The observation journal is defined by Hernádez et al. (2010), as field notes that include descriptions, interpretations, thematic records, personal data, and reactions of the participants. This instrument was used to keep a record of the impressions and happenings in each session during the course. The format of the journal was chosen by the researchers because this way a personal journal can describe the events, impressions, and feelings for each lesson. The test of Navas (2009) on Moral Thinking classifies the levels of moral development with a Likert scale that contains 8 levels. 9 affirmations from both tests and each of them contains 8 answer levels that go 4 by 4 , representing negative numbers a level of discordance to the presented affirmation and the positive numbers to the level of accordance. This test was applied to paper sheets, individually, and one for each session. The test of Enrique was applied in the first sessions and the test of García at the end of the course. The tests are evaluated with the Moral Judgment Test (MJT) on a spreadsheet of Excel that classifies the reason of the answer according to the scheme of Kohlberg, The score shows the level in which is person issues a moral judgment based on the moral conscience: low, regular, high, and very high (Lind, 2010.)

Table I Level of development of exposed arguments, adolescents
Dilemmas were adjusted and adapted to measure the type of moral judgment about a set of reasons present as possible solutions and these dilemmas. The presented dilemmas were the dilemma of Enrique (adapted by Frisancho, 2007), the dilemma of Heinz, the dilemma of Mrs. Garcia (adapted by Fernandez-Cardenas, 2010; see also Nava, 2009), and the dilemma of the evaded inmate. These dilemmas do not have any statistical validity; nevertheless, they have been used in researches of this type.For the personal data questionnaire, a structured interview (specific questions face-to-face) was filled. The questionnaire recorded data of the relative and school data of each participant with the intention to study the intersection between this information and their moral development level. ${ }^{6}$

\section{Results}

The sample participated in a structured interview to gather information about sociodemographic data as academic level, civil state, age, labor, etc. The interview was conducted with the teenagers and their relatives (father, mother, and partner). From this questionnaire of personal data came up this information: ages of participants were of 13,16 , and 17 years old. A total $42.8 \%$ persons were 7 years old and $85.7 \%$ males. $100 \%$ finished elementary school, the third part of the participants finished secondary school, while the rest have not finished their secondary or high school (dropout or in-course.) $33.3 \%$ of the participants had changed school institution during their elementary school, one-third part changed three times, the rest changed twice or once, and $11.1 \%$ repeated a school level. The $77.7 \%$ of participant live with their parents. The most predominant school level for the parents was secondary school. About their jobs, most of them have different activities, and their mothers are stay-home moms. The $45.5 \%$ of the participants have a partner which $55.5 \%$ works with different activities. At the time of the research, the attendance to the treatment course was variable. First, because each participant has different time periods of treatment; and because the participants have to travel long distances to the Preceptory, or because the treatment schedules are difficult due to school or work. Also, there were cases of desertion, a situation that according to the preceptory staff is very recurrent and it represents an obstacle for proper socialization and effective treatment. This Table 1 shows the opinion of the participants on each dilemma.

\begin{tabular}{|c|c|c|c|}
\hline Argument before the lesson & $\begin{array}{l}\text { Level of development } \\
\text { of argument, } \\
\text { according to Kohlberg } \\
\text { theory }\end{array}$ & Argument after the lesson & $\begin{array}{l}\text { Level of development of } \\
\text { argument, according to } \\
\text { Kohlberg theory }\end{array}$ \\
\hline \multicolumn{4}{|l|}{ Dilemma I "The bootlegs" Lesson A9 } \\
\hline $\begin{array}{l}\text { I buy illegal products although they are not } \\
\text { good for the economy. }\end{array}$ & $\begin{array}{l}\text { Pre-conventional level, } \\
\text { stage } 2, \text { "rightness is } \\
\text { relative." }\end{array}$ & $\begin{array}{l}\text { To buy bootlegs is something } \\
\text { illegal but it goes according to our } \\
\text { economy. }\end{array}$ & $\begin{array}{l}\text { Pre-conventional level, stage } \\
2 \text {, "right is relative", "act to } \\
\text { achieve their interests." }\end{array}$ \\
\hline \multicolumn{4}{|c|}{ Dilemma 2 "Bullying Martha" Lesson A4 } \\
\hline $\begin{array}{l}\text { I think that Martha did well to punch the } \\
\text { guy that was humiliating or discriminating } \\
\text { against her. }\end{array}$ & $\begin{array}{l}\text { Pre-conventional level, } \\
\text { stage } 2 \text {, "serve needs and } \\
\text { interests". }\end{array}$ & $\begin{array}{l}\text { Martha had to tell the man what } \\
\text { he did wrong. }\end{array}$ & $\begin{array}{l}\text { Pre-conventional level, step } \\
\text { I, "avoid causing physical } \\
\text { harm." }\end{array}$ \\
\hline \multicolumn{4}{|c|}{ Dilemma 3 "The Dilemma of Mary" Lesson A6 } \\
\hline $\begin{array}{l}\text { It is wrong because men and women are } \\
\text { equal in anything, and the right to study is } \\
\text { equal. }\end{array}$ & $\begin{array}{l}\text { Post-conventional level, } \\
\text { stage } 6 \text {, "continues } \\
\text { universal ethical } \\
\text { principles." }\end{array}$ & $\begin{array}{l}\text { We must respect and hear our } \\
\text { parents but sometimes they are } \\
\text { wrong Mary the same rights and } \\
\text { obligations as children. }\end{array}$ & $\begin{array}{l}\text { Post-conventional level, } \\
\text { stage 6, "continues universal } \\
\text { ethical principles." }\end{array}$ \\
\hline \multicolumn{4}{|l|}{ Dilemma 4 "Peter" Lesson A3 } \\
\hline $\begin{array}{l}\text { Well, he must have called the parents of } \\
\text { Pedro to review the situation further. }\end{array}$ & $\begin{array}{l}\text { Conventional level, stage } \\
\text { 3, "awareness of shared } \\
\text { feelings." }\end{array}$ & $\begin{array}{l}\text { He should call the parents and } \\
\text { analyze the situation and see why } \\
\text { Peter had the cutter as it can be } \\
\text { used for other purposes. }\end{array}$ & $\begin{array}{l}\text { Conventional level, stage } 4 \text {, } \\
\text { "prevent the collapse of the } \\
\text { system." }\end{array}$ \\
\hline
\end{tabular}




\begin{tabular}{|c|c|c|c|}
\hline Argument before the lesson & $\begin{array}{l}\text { Level of development } \\
\text { of argument, } \\
\text { according to Kohlberg } \\
\text { theory }\end{array}$ & Argument after the lesson & $\begin{array}{l}\text { Level of development of } \\
\text { argument, according to } \\
\text { Kohlberg theory }\end{array}$ \\
\hline
\end{tabular}

\section{Dilemma 5 "The briefcase companion" Lesson A6}

Not to say anything to the person that is committing the crime and calls the manager but without him noticing that it was me who reported the crime.
Pre-conventional level, stage 3 , "act according to what people expect."
It should tell for not to commit a breach of law accomplice.
Post-conventional level Stage 5 "sense of obligation to the law."

\section{Dilemma 6 "To you, we are not saying anything" Lesson AI}

It was good because it is shocking when you're paying attention to something and others make fun of that.
Pre-conventional Level I, Phase 2, "follow the rules when immediate interest in someone."
It was good because he respects his shield and because it is annoying.
Level 2, Stage 3, "need to be a good person to oneself and others".

\section{Dilemma 7 "Respect the human species" Lesson A8}

It's okay because there is no money; they need to eat and does not have to take them to the authorities because they are not stealing or anything like that.
Level I, Phase 2, "act to achieve their interests", "it is right what is right".
It is right that they work but at the same time wrong.
Level I, Phase 2, " what is right is relative."

\section{Dilemma 8 "Respect nature" Lesson A5}

Give children a project to raise their grades

Level I, Phase 2, "act to achieve their interests."
Give children a project to raise their grades
Level I, Phase 2, "act to achieve their interests."
By analyzing the arguments, it is concluded that, according to Kohlberg theory (1992), ${ }^{2}$ the level of moral development of teenagers before and after the course was a constant variable between the preconventional level and the conventional level. In Participants, did not show any significant advance at the moment of finishing their lessons. In fact, the same posture was always kept; if there was any modification, it was the necessity to be a "good person" or to act "according to what people expect". These coincide with the established by George Lind (1994) about the discussion programs of moral dilemmas of Kohlberg type, and the minor effects or of short duration on juvenile criminals; also, for the necessity of a broad educative effort for the success of these programs. About the development level, it is confirmed the exposed by Zerpa et al. ${ }^{19}$ about the moral development level on people with alternative treatments to incarceration, concluding that it is a conventional level. Another conclusion of this study is that, although these teenagers should have met a conventional moral level or post-conventional level, their environment has not encouraged a higher development, and as their academic level shows, their studies have been interrupted, living them without a possibility to develop a higher moral and probably cognitive level.

According to the regulation of the Juvenile Reintegration preceptory, it is necessary that the father, mother or tutor of the teenager in treatment attends the program the research had their participation in some of the sessions. The parents information is synthesized on the next Table 2. Again, it can be noticed that the predominant level of the parental guidance of these teenagers is on the pre-conventional level. This level was present after and before the corresponding lesson of each dilemma. This information is an antecedent of the level of moral development of their son or tutored teenager. According to Bandura ${ }^{10}$ who showed that the behavior is learned from parental figures and that in this case, they do not have a mature moral development level leaving the possibility of development that offers the school or the affiliation to any group. Teenagers that have committed crimes or that are prone to commit it have a moral development level has not evolved since their childhood. Table 3 shows the summary of the reached level of moral development of the participants. A: students, T: tutors (parents). As showed in Table 2 after the lessons were finished and the dilemmas analyzed, the moral development results were: for teenager participants of the pre-conventional level and their tutors of conventional level. These results are not a desirable level of the moral development of any of the parties. From the 14 participant students, 7 were positioned on the pre-conventional level, 4 on a conventional level, 1 on post-conventional, and 2 had a mixed level. From the 8 parental participants, 2 were on a pre-conventional level, 5 on a conventional level, and 1 had a mixed level.

The asseveration about the unsatisfactory moral development level that participants need can be based on the studies made by Piaget (1986-1980), in which indicate that according to the age of the participants, all of them should be in an autonomous moral stage of formal operations, according to their biological age. Considering the studies made by Kohlberg (1992); besides biological, moral and cognitive development may count. It is so, participants still are at an unsatisfactory level, since the stage of development they are at the moment, they supposed to be in stages 3 and 5, and tutors on stage 6; which was not met, even after the course. The participant teenagers were submitted to the Moral Judgement Test of Navas (MJT) (Lind, 2010). By evaluating the given answers to two dilemmas; the $C$ score makes the evaluation, this score measures the level in which each person issues a moral judgment in the base of their moral conscience; based on their principles before others. As an example, the opinion of other people; in other words, the $\mathrm{C}$ score shows the ability of the person to judge arguments according to their moral quality over the opinion of other people or factors. C score varies from 1 to 100 a shows the percentage in which the variation of the total individual response of one person about its moral quality. The interpretation scale of C-score is: 1-9 Low, 10-29 Regular, 30-49 High, and 50 or more Very High (Lind, 2010.) Results were organized on the next Figure 1: 
Table 2 The level of development of exposed arguments, parents

\begin{tabular}{|c|c|c|c|}
\hline Argument before the lesson & $\begin{array}{l}\text { Level of } \\
\text { development of } \\
\text { argument provided, } \\
\text { according to } \\
\text { Kohlberg theory }\end{array}$ & Argument after the lesson & $\begin{array}{l}\text { Level of } \\
\text { development of } \\
\text { argument provided, } \\
\text { according to } \\
\text { Kohlberg theory }\end{array}$ \\
\hline
\end{tabular}

Dilemma I "The bootleg discs" Subject T2

\author{
I buy it because an original version is \\ more expensive, with these salaries or you \\ eat, or you buy an original one.
}

"Level I, Phase 2," act to achieve their interests," "what is right is right."

\section{Dilemma 2 "Bullying Martha" Subject T4}

It was wrong because I had to accuse the authorities of the school.

Level 2, Phase 4,

"prevent the collapse of the system."
Typically, isn't bought but if we do and not to affect either side because both sides are legal does it? Better not buy anything.
Level I, Phase 3, "is right what is right".

\section{Dilemma 3 "The Dilemma of Mary" Subject T7}

Mary should talk to her dad and make her understand that she has to study now that the study is important for her and will serve for the future.
Level 3, Phase 5,

"rational individual awareness of the values and rights."
I still think that Martha was wrong, she had to talk to any adult who could help her to avoid aggression.
Level 2, Phase 4, "prevent the collapse of the system."

Level 3, Phase 5, "rational individual awareness of the values and rights."

\section{Dilemma 4 "Peter's cutter" Subject T8}

He wasn't right he should notify the school principal and bring his parents to tell them what he had.
Level I, Phase I, "avoid breaking the rules to avoid punishment."
What you think the pope is very bad I must give equal treatment to all his children; all have the same rights.
Talk to his parents and the child.

Level I, Phase I, "avoid breaking the rules to avoid punishment."

Level I, Phase I, "avoid breaking the rules to avoid punishment."
Yes, that he tells to avoid problems for him and his partner.
Tell the manager alone what is happening because it is a crime and if they realize they can punish him and his partner.
Level I, Phase I, "avoid breaking the rules to avoid punishment."

\section{Dilemma 6 "We weren't talking to you" Subject T2}

He was okay to ask them to respect more to his peers.
Level I, Phase I, "avoid breaking the rules to avoid punishment."
It is important to respect the escort and is something that should be inculcated from home and school.
Level I, Phase I, "avoid breaking the rules to avoid punishment."

Table 3 The summary level of moral development of adolescents and guardians

\begin{tabular}{|c|c|c|c|}
\hline Participants & Level of moral development & Participants & Level of moral development \\
\hline Al & Pre-conventional level. & TI & Conventional level \\
\hline $\mathrm{A} 2$ & Pre-conventional level. & $\mathrm{T} 2$ & Pre-conventional level. \\
\hline $\mathrm{A} 3$ & Conventional level & T3 & Mixed: Pre-conventional and Conventional level \\
\hline A4 & $\begin{array}{l}\text { Mixed: Pre-conventional and Conventional } \\
\text { level. }\end{array}$ & $\mathrm{T} 4$ & Conventional level \\
\hline A5 & Pre-Conventional level. & T5 & Conventional level \\
\hline A6 & $\begin{array}{l}\text { Mixed: Conventional and Post-Conventional } \\
\text { level. }\end{array}$ & T6 & Conventional level \\
\hline A7 & Conventional level. & T7 & Conventional level \\
\hline A8 & Conventional level. & T8 & Pre-conventional level. \\
\hline A9 & Pre-Conventional level. & & \\
\hline AlO & Conventional level & & \\
\hline All & Post-Conventional level & & \\
\hline$A \mid 2$ & Pre-conventional level. & & \\
\hline Al3 & Pre-conventional level. & & \\
\hline $\mathrm{A} \mid 4$ & Pre-conventional level. & & \\
\hline
\end{tabular}




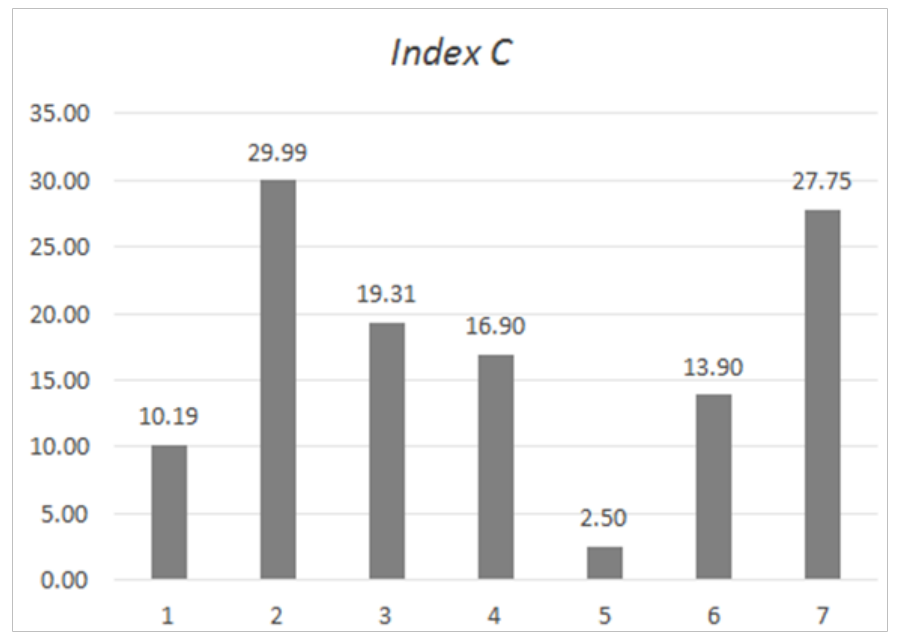

Figure I Test of Navas results interpreted with MJT.

According to the graphic, along the $\mathrm{X}$ axis are placed the participants that answered the test, and along the $\mathrm{Y}$ axis the score on the test. The MJT showed that the average score of participants is under 30, which place them as Regular with a low moral development. Within Kohlberg scale (1992) place them on the conventional and preconventional level. These confirm what the Lind theory (1994) says, that juvenile criminals earn a little by attending to moral discussion programs. Among other reasons, there is a resistance and antisocial posture; on the other hand, statistics confirm the moral development estimation by Zerpa et al. (2006) that people with alternative formulas of penalty compliance, which score under the level according to the alleged cognitive level that they should meet. During the period in which the course Culture of legality was delivered, the impressions, feelings, and behaviors observed by the researchers were recorded on field notes; these were divided into session placing the date and reviewed lesson (Hernandez, Fernandez, Baptista, 2010.). These notes are formed by the obtained after a direct observation by narrating the events of each session, with personal notes about the sensations of the researcher and the reactions of the participants (Hernandez, Fernandez, Baptista, 2010.) Below is exposed a Table 2 with excerpts of the field not. After analyzing the instruments, this research reviews the question, which is the moral development level in teenagers between 12 and 18 years old that have committed any antisocial behavior or that are prone to commit it? To establish which level is between pre-conventional and conventional, by having antecedent on the same moral development level of their tutors and their academic level this results in a no satisfactory moral development level for their age and their supposed corresponding cognitive level. With the above mentioned, it is confirmed what the Kohlberg theory (1992) established by placing the participants with the corresponding description of the pre-conventional and conventional level. Also, the result is similar to the study made by Zerpa et al. (2006) made with a sample of subjects that were out of the prison which indicates the moral development was also conventional. Justicia et al. (2006) concluded that the risk factors for the commission of antisocial behavior resulted of relatives, social and individual type. By comparing those results with this research results, relatives, and individual factors are influential in the low moral development that parents or tutors have, as the style of raising their children. The social factor involves everything related to the academic level; in this research, some of the participants have interrupted their studies or form part of institutions with structural problems; this generates unbalance for the minors.
It is important to mention that low academic level of the parents in contrast with the high index of working teenagers. About their tutors, it is important to make them participate in schools to help the moral development and be informed about the culture of legality. Expectations center on engaging the parents and make them compromise to respect and follow that govern a society to live together in a rule of law (Heredia, Fernandez, Garza, Arredondo, Rozenel, and Castro, 2011), this would be the transmitted behavior to their children. It is important that all the related to the education of teenagers participate in the proposed compromise because the moral development is the ability to distinguish between what is right and incorrect according to the moral norms that rule us. This compromise is the responsibility for tutors and professors with the objective to enter the world of socially responsible citizens (Heredia, Fernandez, Garza, Arredondo, Rozenel, and Castro, 2011.). During the research there were some limiting events; for example, the attendance to the treatment was irregular. The motives could be because each of them has a different established period of treatment (penalty), or the distance they have to travel to the Preceptory or because the treatment schedules are not compatible with their school or labor schedules. Desertion was also a topic of importance.

To continue the research, it is interesting to study the possibility to work in the course of the culture of legality with a selection of teenagers on treatment, external or internal, which penalties confine in similar seasons. It would be interesting to meet different types of results that would be obtained in different tutelary councils, and with those who have no training about the culture of legality, to identify the possible impact that generates a tutor that supports the topic against one who is not gullible with it. Last, it is considered that it can be helpful to research about the level of moral development on teenagers who are trained in the culture of legality courses since pre-school age to pre-adolescence, in comparison with those who have not taken the courses. With this, the impact of early prevention of antisocial behavior could be met given the importance of continuity and reinforcement of the prevention courses during different academic stages.

\section{Acknowledgements}

None.

\section{Conflict of interest}

The author declares there is no conflict of interest.

\section{References}

1. Tesouro M, Palomanes ML, Bonachera F, et al. Estudio sobre el desarrollo de la identidad de la adolescencia. Tendencias pedagógicas. 2013;21:211-224.

2. Kohlberg L. Estadios Morales y Moralización: La vía cognitivoevolutiva. En Psicología del Desarrollo Moral. España: Bilbao: Desclée De Brouwer. 1992. p. 185-214.

3. Heredia Y, Márquez, S. Teorías sobre el desarrollo moral. In Desarrollo moral y competencia ciudadana. México: S/E. 2014. p. 11-29.

4. Barra E. El desarrollo moral: una introducción a la teoría de Kohlberg. Red de Revistas Científicas de América Latina, el Caribe, España y Portugal, 1987:19.

5. Heredia Y, Sánchez A. Teorías del aprendizaje en el contexto educativo. Monterrey, Nuevo León: Editorial Digital Tecnológico de Monterrey. 2013.

6. Hernández R, Fernández C, Baptista P. Metodología de la investigación. México, D.F.: McGrawHill. 2010. 
7. Justicia F, Benítez J, Pichardo M, et al. Aproximación a un nuevo modelo explicativo del comportamiento antisocial. Revista electrónica de investigación psicoeducativa. 2006;9:131-150.

8. Garaigordobil M. Conducta antisocial durante la adolescencia: correlatos socio - emocionales, predictores y diferencias de género. 2005.

9. Espinoza P, Clemente M, Vidal M. Conducta antisocial y desarrollo moral en el menor. Psicothema, 2002;14:26-36.

10. Garrido E, Herrero C, y Masip J. Teoría cognitiva social de la conducta moral y de la delictiva. 2010

11. Colom R, Herrero O. ¿Es verosímil la teoría de la delincuencia de David Lykken? Psicothema. 2006;18(3):374-377.

12. Rodríguez A, Torrente G. Interacción familiar y conducta antisocial. Boletín de Psicología. 2003;78:7-19.

13. Roccatti M. El sistema de prevención social y tratamiento de menores del Estado de México. 1995.

14. Heredia Y, Fernández J, Garza J, et al. Cultura de la legalidad en mi escuela guía para los profesores de secundaria. Monterrey, Nuevo León: Tecnológico de Monterrey. 2011.

15. Heredia Y, Fernández J, Garza J, et al. Cultura de la legalidad en mi escuela guía para padres y madres de familia. Monterrey, Nuevo León: Tecnológico de Monterrey. 2011.
16. Yarto W. La cultura de la legalidad en la familia regiomontana. 2014.

17. Lind G. Why do juvenile delinquents gain little from moral discussion programas? 1994.

18. Lind G. Scoring and Interpreting the Moral Competence test (MCT). 2010 .

19. Zerpa C, Henríquez G, Ramírez J. Estimación del desarrollo moral en una muestra de personas beneficiarias de fórmulas alternativas al cumplimiento de pena en prisión del oriente en Venezuela. Periódicos electrónicos en psicología. 2006;5:284-293.

20. Crespo J. Hacia una cultura de la legalidad. Nueva Antropología. 1990;11:121-129.

21. Michel E. Lidera en delitos el D.F. El Universal. 2013.

22. Valenzuela J, Flores M. El cómo de la investigación: propuesta metodológica. En Fundamentos de investigación educativa Monterrey. México: Editorial Digital del Tecnológico de Monterrey. 2011.p. 71-116.

23. INEGI. Clasificación estadística de delitos 2010. Febrero, 2015, de Instituto Nacional de Estadística y Geografía Sitio. 2010. 